\title{
Introduction to the Special Issue on Territorial Resilience: Mitigation and Adaptation
}

Raul Ramos

AQR-IREA, Universitat de Barcelona, Barcelona, Spain

http://orcid.org/0000-0003-0047-0793

rramos@ub.edu

Vicente Royuela

AQR-IREA, Universitat de Barcelona, Barcelona, Spain

https://orcid.org/0000-0002-7647-0063

vroyuela@ub.edu

\begin{abstract}
In this editorial, we summarize and comment on the six articles published in the Special Issue on Territorial Resilience: Mitigation and Adaptation. The first four articles focus on the analysis of resistance and recoverability after an economic shock. Scuderi et al analyse the relationship between location and resilience of firms by working with micro shops in Uganda. Botezat et al study the role of institutional change on economic and social resilience. Monastiriotis and Martelli (2020) and Geelhoedt et al (2020) analyse the labour market resilience of Greek and Spanish regions, respectively during the Great recession. The last two papers are devoted to renewal, a less studied dimension of resilience. Pontarollo and Serpieri (2020) introduce a novel conceptual framework related to regional economic resilience, namely the renewal capacity. Last, Jimenez-Medina et al provide an interesting case study of a small Spanish town that has successfully moved from being a mining industrial area to a mining heritage tourism place. From our perspective, these articles contribute to a better understanding of the complex sequence between mitigation and adaptation strategies, while they also leave open several questions that could clearly stimulate future research on the topic.
\end{abstract}

\section{Keywords}

Resilience, Regional renewal, Urbanization, Inequality. 
A simple search in the Scopus database with the words "Regional Resilience" returns more than 170 entries in the Social Sciences area published during the last 10 years. The special issue on the "Resilient Region" of the Cambridge Journal of Regions, Economics and Society published in 2010 has an enormous influence to disseminate the concept of resilience across regional scientists. For instance, the paper by Simmie and Martin (2010) has received nearly 600 citations according to Scopus and more than 1200 in Google Scholar while Christopherson et al (2010) or Hassink (2010) have also received considerable attention in terms of citations.

Since then, the research has expanded exponentially addressing both conceptual and measurement issues and applications in different settings. Different meta-analytic reviews have also been published (see, for instance, Sedita, de Noni and Pilotti 2017 or Lazzaroni and van Bergeijk 2014). In fact, as highlighted by Briston and Healy (2020), "part of the richness of the literature surrounding economic resilience is the wide variety of shocks that are subject to examination, ranging from economic shocks and recessionary events, to those that are induced through natural or anthropological events, such as earthquakes, floods, technological shifts or political decisions”. However, as Powley (2020) recognizes, "Resilience scholarship faces confusion: what do we mean by it, or how do we study it?". Moreover, as Mayor and Ramos (2020) highlight, "the complex links between demographic, economic, social and environmental characteristics of territories are not yet fully understood. Further cooperation between these different fields is needed in order to provide a better identification of the factors that can help to improve regional conditions and citizen's quality of life.” For this reason, the AQR Research group decided to devote the 2018 Barcelona Workshop on Regional and Urban Economics to the analysis of territorial resilience with a special focus on mitigation and adaptation strategy. The workshop was held in Barcelona on October $4^{\text {th }}-5^{\text {th }} 2018$ in the Faculty of Economics and Business of the University of Barcelona gathering together more than 30 researchers and practitioners with very different academic and policy backgrounds. This special issue contains some of the papers presented in this workshop while the rest were identified in different conferences and workshops held during 2019. In this editorial, we summarize and comment on the six articles published in this Special Issue.

As takes place in the resilience literature, most works analyze resistance and recoverability after an economic shock putting special attention to the response of agents, and particularly, to the interactions between firms and citizens with administrative and economic regional and urban institutions. This is the case of the first four articles.

The article of Scuderi, Tesoriere, and Fasone (2021) is devoted to study the relationship between location and resilience of firms by working with micro shops in Uganda. Their work explore how territorial development patterns affect local entrepreneurship and its 
longevity. Uganda is one of the fastest growing economies in Sub-Saharan Africa, while its capital city, Kampala, experiences rapid urbanization and economic growth. The authors make use of a unique sample from a direct survey on micro shops located in 10 different cities of Uganda, including both urbanized and remote areas. They understand that firms and their correlation with region-level characteristics (the "business environment”) are key drivers to explain resilience. They use 352 valid survey responses to develop a regression analysis in firms' longevity depends on shop's linkages and location characteristics, while controlling for information on shops, on the manager, and for the influence of natural hazards (e.g. floods). Their results show that higher distance from the capital city is correlated with lower resilience of the business. The findings from value chain variables confirm the importance of the proximity to the main city. They also find that floods, one of the most impacting types of natural hazards is negatively associated with resilience, and that the manager's and business characteristics also matter. The authors suggest that the approach to firm resilience should be based on a deeper linkage between location and entrepreneurship.

Botezat, David, Incaltarau, and Nijkamp (2021) study the role of institutional change on economic and social resilience. They study a change in the judicial status of communities from rural to urban in 2004 in Romania (what they call 'legislative urbanization'). Between 2001 and 2006 the number of towns and cities increased from 265 to 320, being the impact in the urban rate quite low, while there was a clear mismatch between political decisions and urban planning targeting a balanced spatial development and a lack on investment. They use rich administrative data from 2000 to 2014, covering all transformed counties in Romania. And define several indicators to describe resilience capacity: engineering resilience capacity (infrastructure and accessibility), economic resilience capacity (employment and income), social resilience capacity (density, health care and emigration) and a total index of resilience capacity. In order to identify the causal effects, they use a difference-in-difference research design combined with a coarsened exact matching model to make the control and treatment groups. Their findings reveal that the legal reclassification reform has rather reduced resilience capacity in the short-run, being the economic resilience the most affected dimension, mostly due to a financing trap, which increased communes' vulnerability. They find, though, that on the long-term there is positive impact on social resilience capacity, maybe related with their attempt to comply with the legal criteria for urban.

The paper of Monastiriotis and Martelli (2021) also exploits the role of institutions on resilience, in this case from a labor market institutions point of view. They analyze the response to the Great Recession in Greece by measuring the size of the shock exerted on the Greek regional and national labor markets and the compositional and price adjustments in response to this. Using microdata from the Greek Labor Force Survey (LFS) they apply a set of standard micro-econometric and decomposition techniques in a novel way: 1) they 
estimate the contribution of various individual and household characteristics to individual unemployment risk to isolate how the crisis affected the unemployment probability for different active population groups; 2) they develop a decomposition analysis to derive a number of distinct components of the overall change in unemployment, measuring the size of the compositional and price adjustments that took place in response to the shock. Their analysis compares 13 Greek's NUTS2 regions with Athens, the main agglomeration in the country. They find that adjustment to the shock came predominantly through price adjustments, especially in the more urban areas of the country, representing mostly an intensified sorting (into / out of employment) on the basis of some individual characteristics, while some minor quantitative adjustments also took place. According to their results, adjustments in the more recent period of economic recovery seem more promising, with both labor quality and employment sorting on the basis of education improving further, although the geographical differences between Athens and the rest of the country persist. They stress the very prominent role played by the functioning of the labor market for the economic resilience of regions, while there can be substantial regional variations in the degree of labor market adjustments.

Geelhoedt, Royuela and Castells-Quintana (2021) study also employment resilience, in 995 Spanish municipalities during the Great Recession, with a specific focus on income inequality. They have a look at monthly data over the 2003-2018 period and study total employment and at self-employment, which is identified as a mechanism to escape unemployment and a gateway to entrepreneurial activity. They define employment resilience in terms of resistance and recoverability, with specific peaks and troughs for every municipality. Together with income inequality (a potential negative channel for resilience), the also consider other covariates, such as income, sectoral specialization, human capital and innovation, agglomeration and local institutions. Their regression analysis report a negative association between initial levels of inequality and all types of employment resilience, with a significant quadratic term, which implies a severe penalty for highly unequal municipalities, being such effect stronger for self-employment. They conclude suggesting policies fighting inequality as a way to increase resistance of regions to economic shocks.

Finally, we also find two papers devoted to renewal, a less studied dimension of resilience.

The identification and measurement of the regional economic resilience have been focused and carried out mainly with respect to the resistance and recoverability dimensions. Pontarollo and Serpieri (2021) study a novel conceptual framework related to regional economic resilience, namely the renewal capacity. Addressing the whole of NUTS2 EU regions over the 2000-2015 period, they measure employment renewal capacity by looking at the difference between the slopes of the trends before and after the crisis. They find 
higher levels of renewal in the labor market appear in Western Germany, Great Britain, Northern countries, and the Baltics, while Mediterranean countries have been severely affected. Besides, there is a differentiated pattern between old and new EU member states. The authors use a spatial autoregressive models, estimated through maximum likelihood, although they also consider generalized spatial two-stage least squares, and the spatial autoregressive combined model. In order to identify the parameter instability between regions in old and new EU member states they employ a spatial lag switching regression model. Their control variables include income, employment and population, innovation, education and investment, and indices for specialization and diversification. They find employment gender gap and specialization negatively affecting the renewal. Employment level, and trend are always negative for employment renewal highlighting the need for creating productive employment to overcome a shock. The positive impact of the share of higher education is strong among new member states. They conclude recommending policy actions to create the proper condition for non-sticky production factors like capital and patents to produce effects on local markets.

Jimenez-Medina, Artal-Tur and Sánchez-Casado (2021) describe in their article the adaptive resilience path of La Unión, a town located in the southeast of Spain with a long mining tradition which moved from being a mining industrial area to a mining heritage tourism place. The analysis includes two main stages: 1 ) a review and discussion of the process of re-organization of the local economy is carried-out, highlighting the cooperation taking place among the local university and local/regional governments as one key piece in this successful story; and 2) the investigation of the role played by the "place identity" concept in the design and launching of the local tourism model. They use a theoretical model in which place identity sense of residents influences their perception of sociocultural, economic and environmental impacts of tourism, and sequentially, these impact their support to tourism development. By means of a survey ( $\mathrm{N}=381)$ JimenezMedina, Artal-Tur and Sánchez-Casado (2020) capture the whole population features in La Unión. Data analysis employs Partial Least Squares (PLS) in a Structural Equations Modeling (SEM) setting. They first test the capacity of indicators to fit the theoretical constructs and then evaluate the structural model and corresponding significance of the research hypotheses. Key findings show how the process of economic restructuring taking place in La Unión, has had significant effects on how the population perceives the impact of tourism growth now as a positive issue, and on their support for the tourism development process in general. The strongest mechanism found in the paper is the sociocultural one, well above the environmental and the economic. They conclude that place identity experiences would be also allowing for the line-up of the firms and social objectives regarding tourism growth, as building on place identity to launch tourism destinations could ameliorate the negative impacts of tourism for residents. 
Summarizing, the evidence collected in this Special Issue provides an interesting set of results from the academic and the policy perspective. From a policy perspective, the obtained results have shown, for instance, that the case for policy intervention is clearly justified under some circumstances in response to adverse shocks. However, the way in which policies interact along several dimensions provides the perfect framework to consider the possibility of adopting comprehensive policy packages instead of isolated interventions. From an academic perspective, several questions that could clearly stimulate future research on the topic remain still open. For instance, as also suggested by Evenhuis (2017), combining different quantitative and qualitative methods would also be a positive direction for future research in this field. 
References

Botezat, A., David, M., Incaltarau, C., \& Nijkamp, P. (2021). The Illusion of Urbanization: Impact of Administrative Reform on Communities’ Resilience. International Regional Science Review, 44 (1), pp. 33-84. https://doi.org/10.1177/0160017620964861

Bristow, G., \& Healy, A. (2020). "Introduction to the Handbook on Regional Economic Resilience”. In Handbook on Regional Economic Resilience. Cheltenham, UK: Edward Elgar Publishing. doi: https://doi.org/10.4337/9781785360862.00005

Christopherson, S., Michie, J., Tyler, P. (2010). Regional resilience: theoretical and empirical perspectives, Cambridge Journal of Regions, Economy and Society, 3 (1), pp. 310. https://doi.org/10.1093/cjres/rsq004

Evenhuis, E. (2017), New directions in researching regional economic resilience and adaptation, Geography Compass, 11. e12333. https://doi.org/10.1111/gec3.12333

Geelhoedt, F., Royuela, V., \& Castells-Quintana, D. (2021). Inequality and Employment Resilience: An Analysis of Spanish Municipalities during the Great Recession. International Regional Science Review, 44 (1), pp. 113-41. https://doi.org/10.1177/0160017620957056

Hassink, R. (2010), Regional resilience: a promising concept to explain differences in regional economic adaptability?, Cambridge Journal of Regions, Economy and Society, 3 (1), pp. 45-58. https://doi.org/10.1093/cjres/rsp033

Jiménez-Medina, P., Artal-Tur, A., \& Sánchez-Casado, N. (2021). Tourism Business, Place Identity, Sustainable Development, and Urban Resilience: A Focus on the Sociocultural Dimension. International Regional Science Review, 44 (1), pp. 170-199.

https://doi.org/10.1177/0160017620925130

Lazzaroni, S., van Bergeijk, P.A.G. (2014). Natural disasters' impact, factors of resilience and development: A meta-analysis of the macroeconomic literature, Ecological Economics, 107, pp. 333-346, https://doi.org/10.1016/j.ecolecon.2014.08.015.

Mayor, M.; Ramos, R. (2020). Regions and Economic Resilience: New Perspectives. Sustainability, 12, 4693. https://doi.org/10.3390/su12114693 
Monastiriotis, V., \& Martelli, A. (2021). Crisis, Adjustment and Resilience in the Greek Labor Market: An Unemployment Decomposition Approach. International Regional Science Review, 44 (1), pp. 85-112. https://doi.org/10.1177/0160017620964848

Pontarollo, N., \& Serpieri, C. (2021). Challenges and Opportunities to Regional Renewal in the European Union. International Regional Science Review, 44 (1), pp. 142-169.

https://doi.org/10.1177/0160017620931591

Powley, E. H. (2020). “Introduction: framing resilience research”. In Research Handbook on Organizational Resilience. Cheltenham, UK: Edward Elgar Publishing. doi:

https://doi.org/10.4337/9781788112215.00006

Scuderi, R., Tesoriere, G., \& Fasone, V. (2021). Does Location Matter for Micro Shops Resilience? Evidence from Uganda. International Regional Science Review, 44 (1), pp. 1032. https://doi.org/10.1177/0160017620931582

Sedita, S. R., De Noni. I. \& Pilotti. L. (2017). Out of the crisis: an empirical investigation of place-specific determinants of economic resilience, European Planning Studies, 25 (2), pp. 155-180, https://doi.org/10.1080/09654313.2016.1261804

Simmie, J., Martin, R. (2010), The economic resilience of regions: towards an evolutionary approach, Cambridge Journal of Regions, Economy and Society, 3 (1), pp. 27-43. https://doi.org/10.1093/cjres/rsp029 